\title{
Pure Primary Small Cell Carcinoma of Urinary Bladder: An Ex- treme Rarity
}

\author{
Sanjay Kumar, Namita Bhutani*, Sant Prakash Kataria and Rajeev Sen
}

Department of Pathology, PGIMS Rohtak, Haryana, India

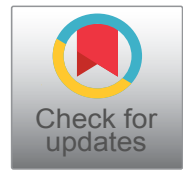

*Corresponding author: Namita Bhutani, Department of Pathology, PGIMS Rohtak, Haryana, India, Tel: +91-9873101393, Fax: +91-1262-281308

\begin{abstract}
Small cell carcinoma of the urinary bladder is an extremely rare tumor accounting for less than $1 \%$ of all cancers arising from the bladder. Since the tumor is very rare, pathogenesis is uncertain. The tumor shares similar histological features with the small cell carcinoma originating at the other sites in body. However, its similar clinical features like the conventional transitional cell carcinoma of the bladder, tendency to present at a advanced stage and low immunoreactivity to the conventional neuroendocrine markers makes the early diagnosis challenging and simultaneously crucial for the patient's survival. The unknown etiology and natural history of small cell carcinoma of the urinary bladder represent a challenge both to the pathologist and urologists for its diagnosis and treatment, respectively. Considering the very few numbers of case reports available in the literature and lack of the definitive data predicting the therapeutic response to various modalities, we, herein, describe a case of small cell carcinoma originating in the urinary bladder in a female patient who was treated at our institute.
\end{abstract}

\section{Keywords}

Neuroendocrine, Small-cell carcinoma, Urinary bladder carcinoma

\section{Introduction}

Small cell carcinoma of the bladder is a highly aggressive, poorly differentiated neuroendocrine neoplasm accounting for only $0.3-0.7 \%$ of all bladder tumors. Recently, molecular studies have indicated that small cell carcinoma and urothelial cancer are derived from the same clonal population, though the tumor is still classified as a discrete entity $[1,2]$. Its management is challenging because it presents in the similar way like other more frequent histological types, but with a high metastatic potential and is refractory to treatment. To im- prove the life expectancy, a multidisciplinary approach including radical cystectomy, chemotherapy, and radiation therapy should be initiated as soon as possible. In the present article we report a case of a female patient with small cell carcinoma of the bladder and emphasize its rarity as well as the role of immunohistochemistry.

\section{Case Report}

A 63-year-old female presented to urology outpatient department with complaints of hematuria. The patient's urine examination was positive for blood with microscopic presence of 3-7 RBC/hpf. The ultrasonography of the urinary bladder revealed a large flat mass measuring $4 \times 2 \mathrm{~cm}$ arising from dome and anterior wall of urinary bladder. Contrast enhanced computed tomography scan confirmed the anatomical location of the mass. Patient underwent cystoscopy and transurethral resection (TUR) of the mass. Microscopic sections showed sheets and nests of loosely cohesive, small round to oval cells with hyperchromatic coarsely granular nuclear chromatin, scant cytoplasm and marked crushing artefact (Figure 1). Immunohistochemically, the tumor cells stained positive for cluster of differentiation (CD) 56, chromogranin A, and synaptophysin, (Figure $2 \mathrm{~A}$, Figure $2 \mathrm{~B}$ and Figure $2 \mathrm{C}$ ) and were negative for NSE, epithelial membrane antigen and leucocyte common antigen. The pathology of resected mass was primary small cell carcinoma invading muscularis propria. The patient's whole-body scan had no evidence of metastasis. Faced with the diagnosis, the attending team chose to perform radical cystectomy (RC) and ileal conduit urinary diversion and standard lymph node dissection under general anesthesia. The patient had no

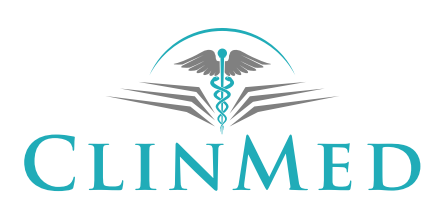

INTERNATIONAL LIBRARY
Citation: Kumar S, Bhutani N, Kataria SP, Sen R (2018) Pure Primary Small Cell Carcinoma of Urinary Bladder: An Extreme Rarity. Int Arch Urol Complic 4:043. doi.org/10.23937/2469-5742/1510043 Accepted: September 17, 2018: Published: September 19, 2018

Copyright: (C) 2018 Kumar S, et al. This is an open-access article distributed under the terms of the Creative Commons Attribution License, which permits unrestricted use, distribution, and reproduction in any medium, provided the original author and source are credited. 


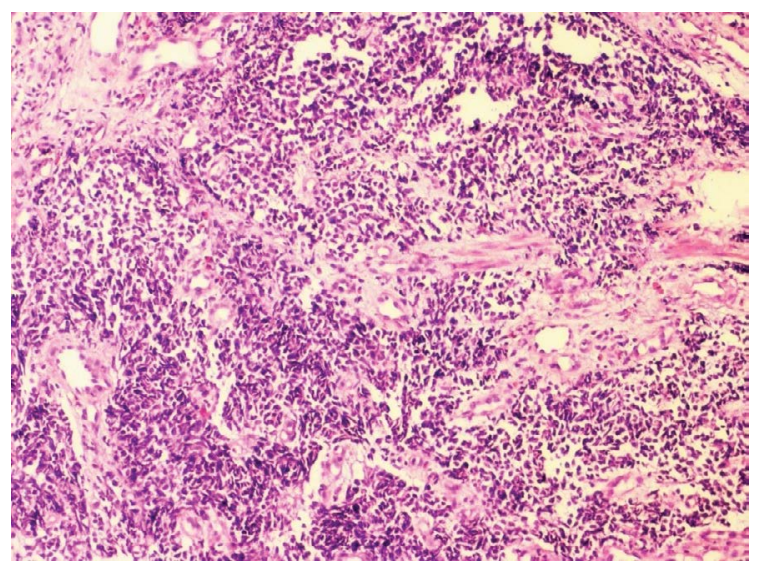

A

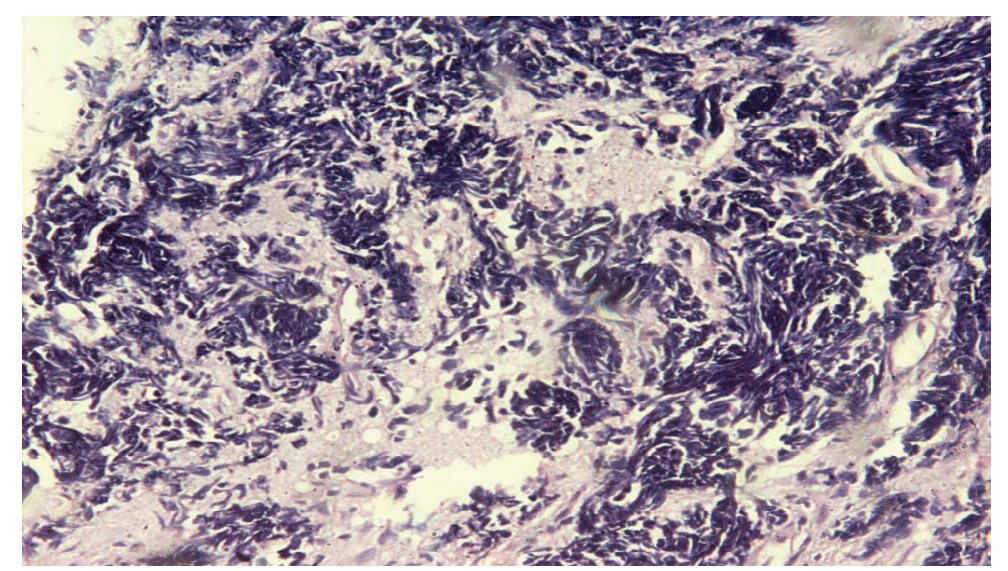

B

Figure 1A: Tumor cells are arranged in sheets and clusters and are invading the muscle fibres (H\&E, 40X).

Figure 1B: Tumor cells contain scant amount of cytoplasm and oval to spindle hyperchromatic nuclei. Nucleoli are inconspicuous (H\&E, 100X).

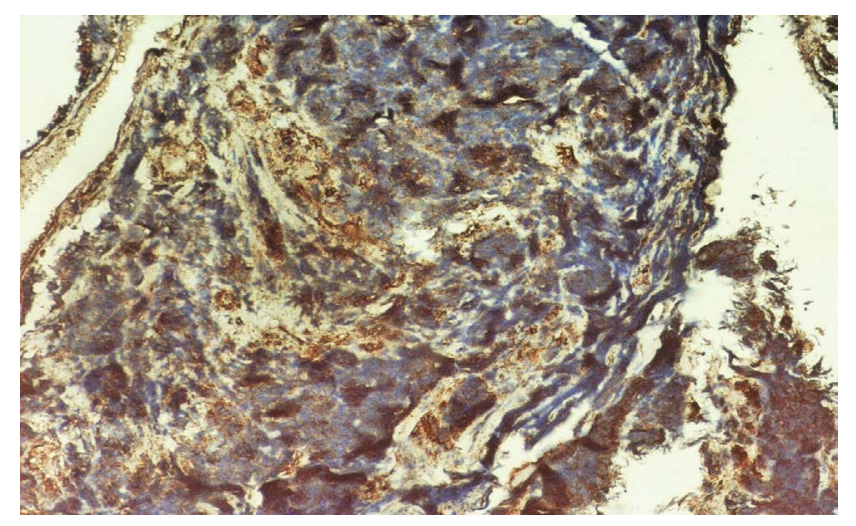

Figure 2A: Synaptophysin positivity in tumor cells (100X).

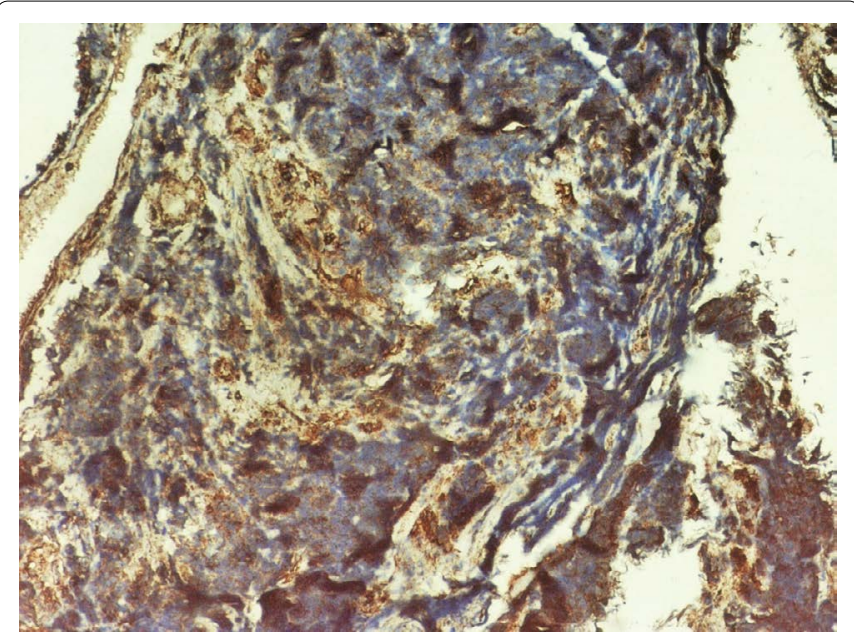

Figure 2B: Chromogranin positivity in tumor cells (100X).

complications after RC and she was discharged on day 19 after RC. She was also given neo adjuvant chemotherapy (received four cycles of cisplatin, gemcitabine and paclitaxel) and is doing well.

\section{Discussion}

Neuroendocrine tumors can arise in almost all organs and are commonly encountered in the respiratory and gastrointestinal tract while involvement of the urinary

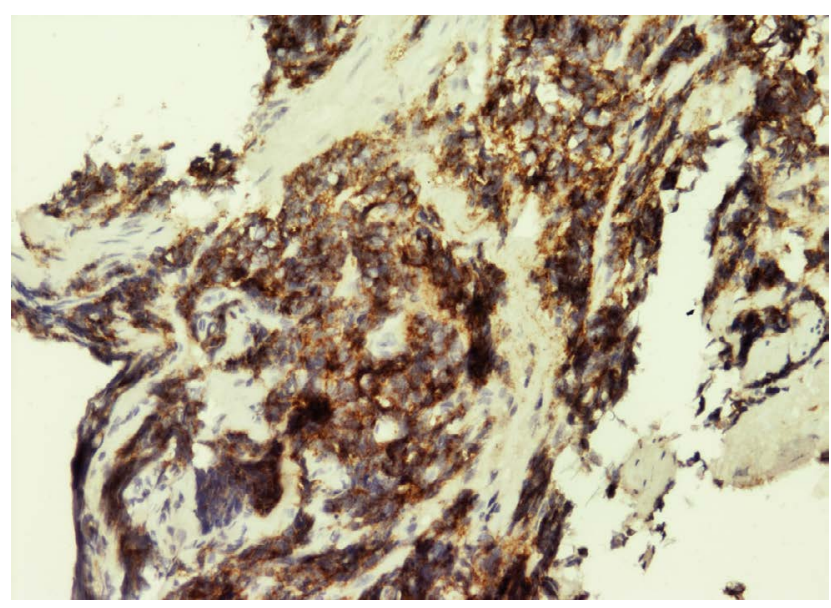

Figure 2C: CD56 positivity in tumor cells (100X).

bladder is very rare. Small cell carcinoma of bladder (SmCCB) was firstly reported in 1981 by Cremer, et al. [3]. The male: female prevalence ratio of SmCCB is 5:1, and the average age of onset is approximately 67 years (range: 32-91 years) [1]. Small cell carcinoma of bladder has similar characteristics of age, sex, and symptoms as of transitional cell carcinoma (TCC). That is why it is a diagnostic challenge, depending only on the skills of the pathologist to differentiate it from urothelial carcinoma, which beside the factors already mentioned, has the same radiological aspect of small cell carcinoma of the bladder. Cigarette smoking, bladder calculi and long-term cystitis are thought to be the etiological factors involved in its pathogenesis [2]. Patients typically present with hematuria. Tumors are usually large and polypoid or nodular and may have an ulcerated surface. The lateral bladder walls are the most common site. Epidermal growth factor receptor (EGFR) protein expression and gene amplification were evaluated in small cell carcinoma of bladder, and presence of these was correlated with the pathological stage of this tumor. On the other hand, DNA methylation can be used as a biomarker in the diagnosis, treatment, and follow-up of small cell carcinoma of bladder [4]. 
Because of the rarity and the resulting paucity of clinical trials, no definitive treatment algorithm for the disease has yet been described. Radical cystectomy is considered as the best method to completely eliminate the small cell carcinoma of the bladder, but it improves survival only in the localized tumor. Moreover, in addition to radical cystectomy, extended lymph node dissection can increase the survival rate. In advanced stages, cisplatin-based chemotherapy should be considered as the treatment of choice for patients with good performance status and good renal function. The treatment should be based on neuroendocrine regimen- etoposide plus cisplatin or ifosfamide plus doxorubicin at day 1 and etoposide plus cisplatin at day 21. Despite therapy, the long-term prognosis is poor, with a $16 \% 5$-year survival. Lymph node metastases occur in $66 \%$ of cases, with distant metastases occurring in the liver, bone and lung $[5,6]$. The present case though presented with a large tumor mass along with muscle invasion, responded well to combination therapy of surgical resection followed by systemic chemotherapy.

\section{Conclusion}

Small cell carcinoma of the bladder is considered to be extremely aggressive and there is less known information about its pathogenesis and molecular biology. As a result of the rarity of this neoplasm, data on the ideal approach for this kind of tumor are scarce, showing the importance of reporting such cases and, in this way, defining the best diagnostic and treatment methods.

\section{References}

1. Cheng L, Jones TD, McCarthy RP, Eble JN, Wang M, et al. (2005) Molecular genetic evidence for a common clonal origin of urinary bladder small cell carcinoma and coexisting urothelial carcinoma. Am J Pathol 166: 1533-1539.

2. Trias I, Algaba F, Condom E, Español I, Seguí J, et al. (2001) Small cell carcinoma of the urinary bladder. Presentation of 23 cases and review of 134 published cases. Eur Urol 39: 85-90.

3. SF Cramer, M Aikawa, M Cebelin (1981) Neurosecretory granules in small cell invasive carcinoma of the urinary bladder. Cancer 47: 724-730.

4. Wang X, Zhang S, MacLennan GT, Eble JN, Lopez-Beltran A, et al. (2007) Epidermal growth factor receptor protein expression and gene amplification in small cell carcinoma of the urinary bladder. Clin Cancer Res 13: 953-957.

5. Cheng L, Pan CX, Yang XJ, Lopez-Beltran A, MacLennan GT, et al. (2004) Small cell carcinoma of the urinary bladder: A clinicopathologic analysis of 64 patients. Cancer 101: 957-962.

6. Omar Hamdy, Khalid Atallah, Amira K El-Hawary, Gehad Saleh, Gena M Abdelazeem, et al. (2017) Primary small cell carcinoma of the urinary bladder in association with bilharziasis: A case report from Egypt. Current Medicine Research and Practice 7: 194-197. 